\title{
SOME INEQUALITIES AND PROPERTIES CONCERNING CHORDAL POLYGONS
}

\author{
MIRKO RADIĆ
}

Abstract. The paper deals with some inequalities and properties concerning chordal polygons. The Theorems $1-3$ are proved.

Mathematics subject classification (1991): 51E12.

Key words and phrases: inequality, $k$-chordal polygon. 